\title{
Patrimônio, Religião e Identidades na cidade de Goiás
}

\author{
Heritage, Religion and Identities in the city of Goiás \\ Patrimonio, Religión e Identidades en la ciudad de Goiás
}

Fernando Martins dos Santos

Universidade Federal de Goiás (UFG), Brasil

prof.fernandosantos@globo.com

Yussef Daibert Salomão de Campos

Universidade Federal de Goiás (UFG),, Brasil

yussefcampos@ufg.br
DOI: https://doi.org/10.18472/cvt.21n2.2021.1947

Redalyc: https://www.redalyc.org/articulo.oa?

id $=115468015008$

\section{Resumo:}

A Cidade de Goiás, fundada em 1727, foi capital do Estado por mais de 200 anos. Durante toda a história - e, em especial, no processo de sua patrimonialização -, sua relação com a religião católica esteve presente, e, já no século XVII, foram construídas oito igrejas. Eram nelas que os vilaboenses tinham contato com a arte, principalmente, a partir do século XIX, com as obras de Veiga Valle. A possibilidade de transferência da Capital sempre foi um assunto recorrente pelos governantes, fato que acabou ocorrendo em 1937. Com receio de que a cidade desaparecesse, os vilaboenses apegaram-se ao que mais se orgulhavam: sua história, criando a narrativa da cidade de Goiás ser o berço da cultura goiana. Para isso, usaram o tombamento da cidade, fato que iria afirmar a identidade vilaboense como berço cultural goiano. Dessa maneira, o destaque foi para suas igrejas coloniais e arte sacra, que foram os primeiros bens tombados na cidade.

Palavras-chave: Patrimônio religioso, Cidade de Goiás, identidade, SPHAN.

\section{Abstract:}

The City of Goiás, founded in 1727, was the capital of the State for more than 200 years. Throughout its history - and specially regarding the history of its patrimonial status -, its relationship with the Catholic religion was present, and, in the 18th century, eight churches were built. It was in the churches that the vilaboenses had contact with art, mainly, from the 19th century, with the works of Veiga Valle. The possibility of transferring the capital has always been a recurring issue by government officials, a fact that ended up occurring in 1937. Fearful that the city would disappear, the villagers clung to what they were most proud of its history, creating the narrative of the city of Goiás to be the cradle of Goiás culture. For this, they will use the city's topography, a fact that would affirm the vilaboense identity as a cultural cradle from Goiás. In this way, the highlight was its colonial churches and sacred art, which were the first goods recorded in the city.

KEYWORDS: Religious heritage, City of Goiás, identity, SPHAN.

\section{Resumen:}

Cidade de Goiás, fundada en 1727, fue la capital del Estado durante más de 200 años. Durante su historia - y, en particular, en el proceso de su patrimonialización - estuvo presente su relación con la religión católica y, en el siglo XVII, se construyeron ocho iglesias. Fue en las iglesias donde los lugareños tuvieron contacto con el arte, principalmente, del siglo XIX, con las obras de Veiga Valle. La posibilidad de trasladar la capital siempre ha sido un tema recurrente por parte del gobierno, hecho que acabó ocurriendo en 1937. Temerosos de que la ciudad desapareciera, los pobladores se aferraron a lo que más orgullosos tenían: su historia, creando la narrativa de la ciudad de Goiás será la cuna de la cultura Goiás. Para ello, aprovecharán las propinas de la ciudad, hecho que afirmaría la identidad de vilaboense como cuna cultural de Goiás. De esta manera, lo más destacado fueron sus iglesias coloniales y el arte sacro, que fueron los primeros bienes registrados en la ciudad.

Palabras Clave: Patrimonio religiosa, Ciudad de Goiás, identidad, SPHAN. 


\section{INTRODUÇÃO}

A Cidade de Goiás é conhecida por suas referências patrimoniais, tendo recebido o título de Patrimônio Cultural da Humanidade em 2001, junto à Organização das Nações Unidas para a Educação, a Ciência e a Cultura (UNESCO), e com seus primeiros tombamentos pelo SPHAN[1], ainda em 1950, por meio da inscrição de quatro de suas igrejas e uma imagem de Nossa Senhora do Rosário, de autoria de Veiga Valle. O seguinte texto tem como pretensão discutir a importância desse patrimônio religioso para o processo dos primeiros tombamentos, e das relações que esse momento proporcionou para se forjar e se fortalecer uma identidade vilaboense, nas bases de um discurso que indica a cidade como berço da cultura goiana.

Entende-se por patrimônio religioso de natureza material, segundo Percival Tirapeli (2020), as formas arquitetônicas dos templos (igrejas, sinagogas, capelas, entre outros) e são complementadas pela tradição da representação das entidades evocadas por meio das esculturas, pinturas e outros objetos. No Brasil, a preservação desses patrimônios está relacionada aos marcos fundadores das vilas coloniais, de religiosidades e de irradiação e cultura, a partir de estilos artísticos de arquitetura, pintura, escultura e memória (bem como símbolos do poder político da Igreja Católica); tais templos estão inseridos nas malhas urbanas, sendo, muitas vezes, destaque visual e artístico. Compuseram também importante capítulo nas narrativas historiográficas sobre a construção da identidade nacional, sendo, dessa maneira, os mais contemplados nos primeiros processos de tombamento do Serviço do Patrimônio Histórico e Artístico Nacional (Tirapeli, 2020). A Cidade de Goiás, com suas quatro igrejas tombadas, sendo uma com imagem sacra de Veiga Valle, é exemplo claro desse mostrado por Tirapeli (2020).

Alguns apontamentos sobre as primeiras atuações do Serviço do Patrimônio Histórico e Artístico Nacional serão oportunamente levantados. Segundo Márcia Chuva (2009), essas atuações se deram dentro de uma política de Estado, de parâmetros nacionalistas, tendo como projeto uma "unidade nacional" que tinha o catolicismo, o legado colonial e a ocupação portuguesa do território como importantes elementos de coesão. Para isso, no Brasil, o patrimônio histórico e artístico privilegiado foram os exemplares da arquitetura tradicional do período colonial (Chuva, 2009), como foi o caso da Cidade de Goiás, fundada no século XVIII. Daí o enfoque deste artigo nesses elementos de uma narrativa patrimonial consagrada e acionada politicamente.

\section{A ANTiga CAPital, AS IgRejas E O SANTEIRo}

A antiga capital, atualmente nomeada Cidade de Goiás, teve sua fundação na época do chamado Ciclo do Ouro. Em 1722, o bandeirante Bartolomeu Bueno da Silva, o Anhanguera, organizou uma expedição que sairia de São Paulo à procura de ouro, prata e pedras preciosas, "depois de três anos e três meses, a 21 de outubro de 1725, retornam os sobreviventes a São Paulo” (Palacin, 1994, p. 21). No ano seguinte, 1726, Bueno parte em definitivo para Goiás, para iniciar a exploração do ouro encontrado às margens do Rio Vermelho, naquele mesmo ano fundou os arraiais de Ferreiro, Ouro Fino, da Barra e de Sant 'Anna.

Em 1737, o Conde de Sarzedas foi encarregado de instalar a primeira vila no território goiano, mas acabou morrendo no percurso da viagem, no arraial de Traíras (Assis, 2005). Somente em 1739 que Dom Luiz de Mascarenhas fez a instalação da vila, na qual o antigo arraial de Sat' Anna tornou-se Vila Boa de Goiás (em homenagem a Bartolomeu Bueno). Em 1744, Goiás foi desmembrado de São Paulo criando a Capitania de Goyaz, tendo como capital Vila Boa. Em 1818, a pedido do bispo D'Azato, da prelazia de Goiás, Vila Boa de Goyaz foi elevada a cidade, recebendo o nome de Cidade de Goyaz, nome que mantém até os dias atuais.

Como em toda colônia, o catolicismo na Cidade de Goiás esteve presente desde a sua fundação. Não é possível ou interessante ler as igrejas na Cidade de Goiás apenas como indicação da devoção de seu povo, mas sim, eram como um "símbolo de civilização" proposto para aquela localidade. Na cidade as igrejas eram numerosas e destacam-se como as construções mais imponentes, rivalizando diretamente com as 
construções públicas (Câmara e Cadeia e o Palácio Conde dos Arcos). No entanto, se deve salientar que essa monumentalidade das igrejas da antiga capital deve ser considerada em critérios internos e locais; usando outras regiões como parâmetro, elas perderiam sua imponência (Oliveira, 2014).

A antiga capital já contou com oito igrejas, sendo elas: Matriz de Sant'Ana, Nossa Senhora do Rosário dos Pretos, Nossa Senhora da Boa Morte, Nossa Senhora da Lapa (que foi arrastada pela enchente de 1839), Nossa Senhora do Carmo, São Francisco de Paula, Santa Bárbara e Nossa Senhora da Abadia. A maioria dessas igrejas mantiveram sua estrutura original, sendo exceções a Matriz de Sant'Ana e a Igreja de Nossa Senhora do Rosário.

A primeira igreja a ser erguida, no ainda arraial de Sant'Ana, foi a capela de Sant'Ana, em 1727, por Bartolomeu Bueno da Silva. Para que tivesse as dimensões mais adequadas, em 1743, a capela foi demolida para que se construísse a Igreja Matriz de Sant 'Ana (Figura 1). Todo o seu teto caiu no ano de 1759, "servindo então de matriz o Rosário, depois de estar muito tempo deixada, a ponto de crescer mato no seu interior, foi consertada pelos devotos" (Padre Luís Antônio da Silva e Sousa apud Etzel, 1974, p. 192).

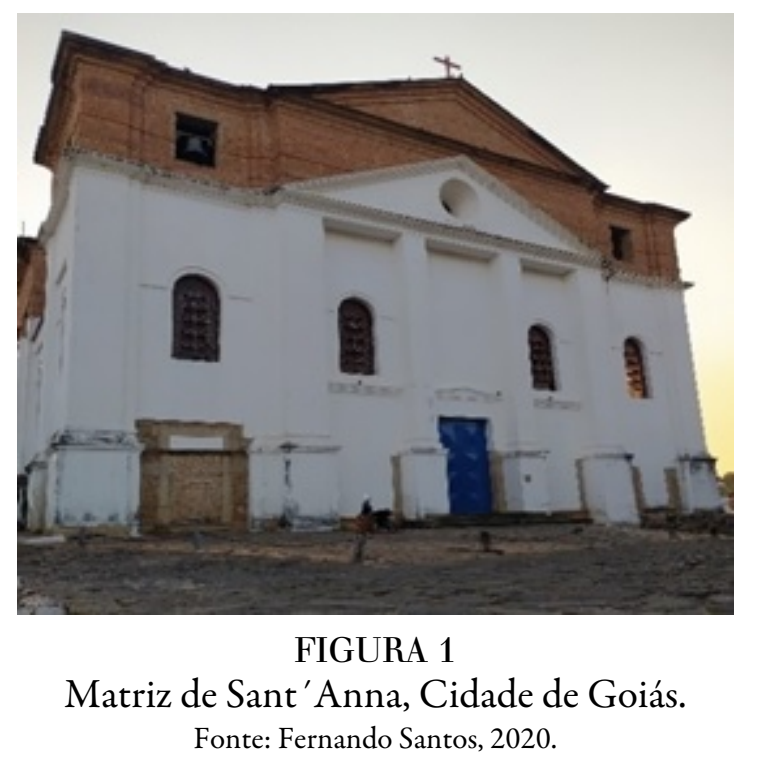

Durante todo o século XIX, a matriz passou por reformas para corrigir rachaduras que insistiam em aparecer, levando a ocorrer alguns desabamentos. Sendo impossível continuar com as celebrações religiosas, em 1874, a igreja foi desativada e a Catedral foi transferida para a Boa Morte. Antes de ser desativada, Cunha Mattos (1894), em sua passagem pela região em 1824, fez uma detalhada descrição da igreja:

A igreja matriz ou catedral da prelazia dedicada a Sant 'Ana: é mui espaçosa e tem 9 altares. O altar-mor é obra soberba. Tem colunas de madeira de grandeza notável, e acha-se muito bem dourada. Os altares colaterais são mui asseados, e nenhum deles está em capela funda. Nesta igreja e em todas as outras da prelazia não há catacumbas: os cadáveres enterram-se nas igrejas; e pelos campos há vários cemitérios para a gente pobre, que falece distante dos lugares em que há igrejas. Há ricas peças de prata nesta igreja, e tem as confrarias do Sacramento, Sant 'Ana, Santo Antônio dos militares e empregados públicos; e a do Senhor dos Passos em uma grande capela na parte posterior dos altares colaterais do lado da epístola (Mattos, 1874, p. 315).

Em 1929, estando em ruínas, contratou-se um projeto para o arquiteto Gastão Bahiana, da Escola de Belas Artes do Rio de Janeiro. O projeto deveria aproveitar os alicerces originais, mas no andamento das obras percebeu-se que os alicerces eram incapazes de suportar o peso das paredes e as torres dos sinos, sendo assim, o projeto foi sendo adaptado ao longo dos anos. Somente em 1965 a igreja voltou a realizar os cultos e em 1967 retornou como Catedral.

A Igreja de Nossa Senhora do Rosário dos Pretos (Figura 02) foi construída em 1734 pela Irmandade de Nossa Senhora do Rosário. Possuía uma decoração simples, com talhas douradas e pintura policromada e o interior com pequenos buquês, porta do sacrário em talha barroca (Passos, 1968, p. 18), e ainda contava 
“com três altares, capela mor profunda e bem ornada" (Mattos, 1874, p. 316). Em 1934, a Igreja do Rosário é demolida e uma nova, em estilo neogótico, é construída (Figura 3).

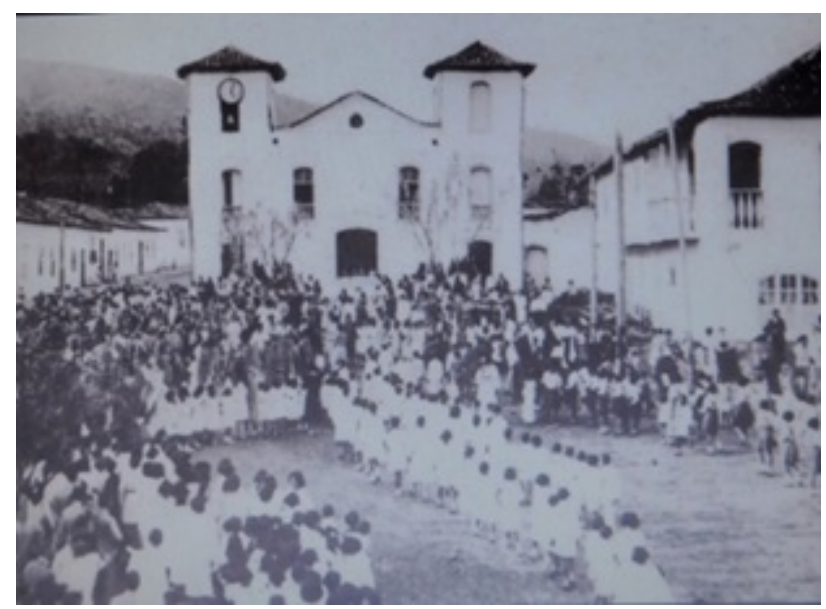

FIGURA 2

Antiga Igreja do Rosário, Cidade de Goiás Fonte: Acervo Frei Simão Dorvi (s.d.).

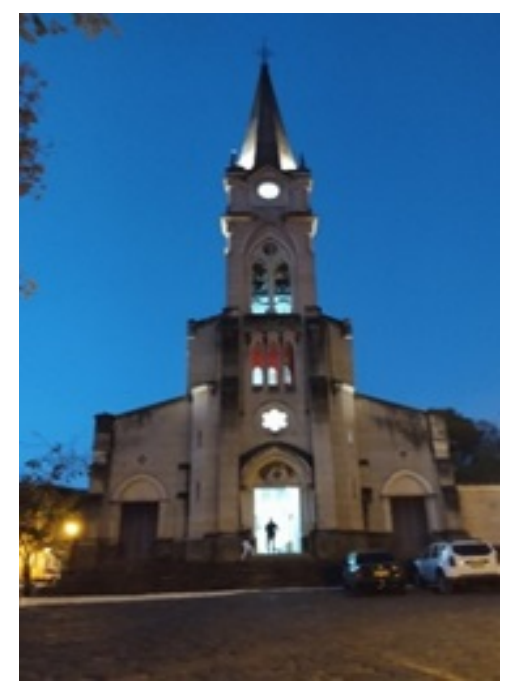

FIGURA 3

Atual Igreja do Rosário, Cidade de Goiás.

Fonte: Fernando Santos, 2020.

A Igreja de São Francisco de Paula foi concluída em 1761, localizada em um pequeno morro, tendo uma escadaria de acesso e um cruzeiro, possuindo uma simples fachada, de estilo colonial, uma com um campanário externo, com armação de madeira e dois sinos (Figura 4). No seu interior tinha um arco do cruzeiro, um sacrário de talha muito simplificada; o altar-mor é de linhas simples, mas na parte de cima há duas conchas, acima das cornijas (Etzel, 1974). Em 1869, o pintor André Antônio da Conceição foi contratado para pintar o tema da vida de São Francisco de Paula, temas da liturgia e florais no seu forro. Outras "pinturas decorativas podem ser encontradas nas sobrevergas das portas de ligação interna da nave com os corredores laterais e no púlpito" (Coelho, 1999, p.74). Em 1873, passou a abrigar a Irmandade de Nosso Senhor dos Passos, quando a sua imagem foi colocada no altar-mor, permanecendo até os dias atuais. 


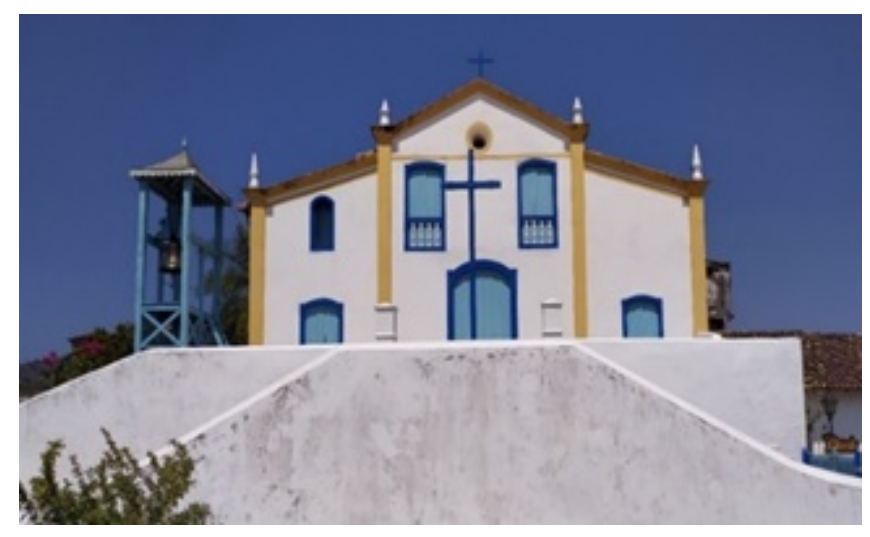

FIGURA 4

Igreja São Francisco de Paula, Cidade de Goiás

Fonte: Fernando Santos, 2020.

Em 1779, foi construída a Igreja de Nossa Senhora da Boa Morte (Figura 5), que "segundo voz corrente, em terreno onde existiu uma das casas de Bartolomeu Bueno da Silva” (Coelho, 1999, p.41). Com formato octogonal irregular, "a fachada em estilo barroco com frontispício característico e único no gênero entre as igrejas em Goiás” (Etzel, 1974, p. 192), com três altares, sendo o principal dedicado à Nossa Senhora da Boa Morte e os laterais dedicados à Nossa Senhora das Dores e a Nossa Senhora do Parto. Na sua sacristia existia um quadro de autor desconhecido representando a Última Ceia, e o sino ficava externamente em uma torre. Teve suas atividades interrompidas em 1967, quando passou a abrigar o Museu de Arte da Sacra.

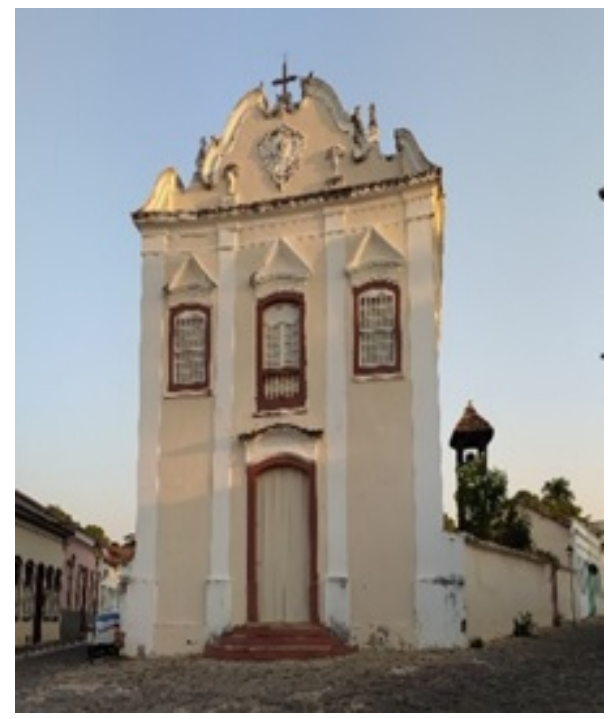

FIGURA 5

Igreja de Nossa Senhora da Boa Morte, Cidade de Goiás.

Fonte: Fernando Santos (2020)

A menor das igrejas era a de Santa Bárbara (Figura 6), que se situava no alto de uma pedreira, tendo uma grande escadaria que "teria sido originalmente de pedra-sabão, posteriormente substituído por cimento" (Coelho, 1999, p.95). Foi construída em 1780, com paredes lisas, possuindo dois campanários (Mattos, 1874). O seu interior era composto por paredes e arco do cruzeiro liso, com "um único altar de um modesto barroco-rococó, com trabalho de talha no sacrário e na moldura que circunda o nicho central profundo; ao que nos pareceu nunca foi dourado" (Etzel, 1974, p. 194). 


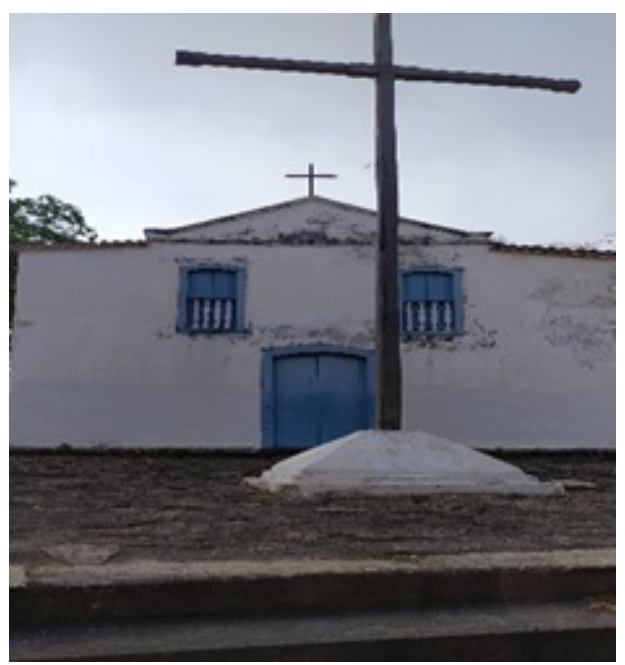

FIGURA 6

Igreja de Santa Bárbara, Cidade de Goiás

Fonte: Fernando Santos (2020).

A Igreja de Nossa Senhora do Carmo foi construída em 1786 (Figura 7), sendo sua fachada bem simples, quase se confundindo com a das residências ao seu redor, diferenciando-se somente pelo frontão triangular reto e com um óculo. Seu interior era composto por três altares em talha, inspirado numa mistura de barroco e neoclássico e, por isso, acredita-se que foram feitos posteriormente. "Os arcos de sustentação do coro, sendo o arco central com arcada lisa e os laterais com curvaturas que lembram as arcadas góticas e mouriscas" (Etzel, 1974, p. 193). O espaço interno era bastante movimentado devido os arcos, possuía janelas internas, tribunas e inúmeros compartimentos, originalmente para uso da irmandade de São Benedito dos Homens Pardos Crioulos (Coelho, 1999).

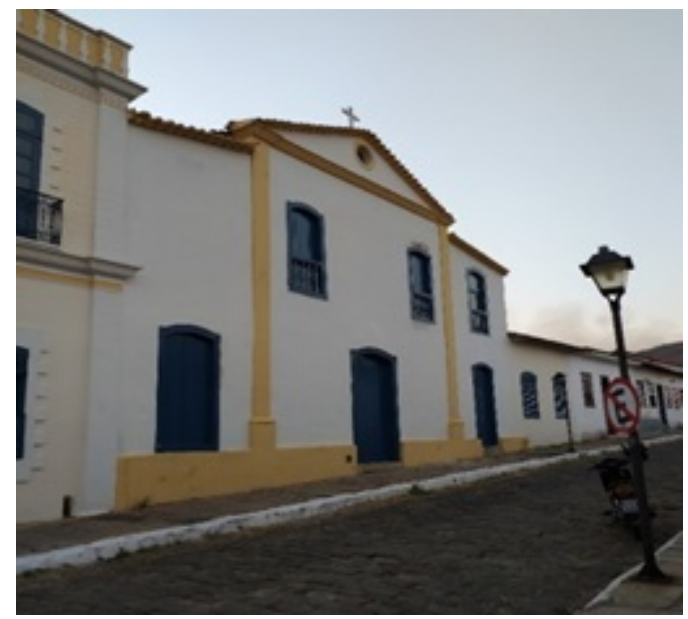

FIGURA 7

Igreja de Nossa Senhora do Carmo, Cidade de Goiás.

Fernando Santos (2020).

A última das igrejas, em estilo colonial, foi construída em 1790, financiada com esmola do povo, em homenagem a Nossa Senhora da Abadia (Figura 8). A sua fachada tem uma porta de talha almofadada e mais duas janelas, e o frontão é formado por uma parte central mais alta que destaca uma pequena cruz de madeira, sendo que suas laterais são mais baixas, com uma pinácula em cada canto. À sua direita há um campanário, onde existia um relógio (Mattos, 1874, p. 316). No interior da igreja o teto foi todo decorado com pinturas de autoria desconhecida, que representam Nossa Senhora no céu e entre anjos. Para Etzel, 
O interior é fascinante: arco cruzeiro de madeira, com capitéis e cornijas de madeiras, tendo o corpo vertical liso de secção triangular. Este arco emoldura a capela-mor onde se vê um altar de barroco simplificado, com 4 colunas lisas e talha enfeitando a vase, incluindo o sacrário todo trabalhado. O nicho profundo é emoldurado por fina talha; no arco superior do retábulo há, além da talha, 4 florões que dão acabamento às colunas. Já no corpo da igreja, destaca-se a beleza da mesa de comunhão, com colunas de recorte e um pequeno confessionário do mesmo estilo. Notável ainda o púlpito, cuja frente é toda enfeitada de talha rendada de pouco relevo (Etzel, 1974, p.194).

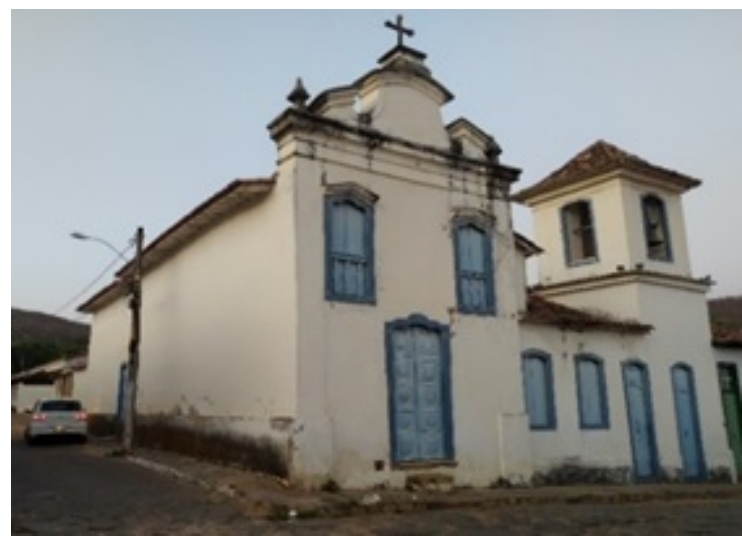

FIGURA 8

Igreja de Nossa Senhora da Abadia, Cidade de Goiás. Fonte:Fernando Santos (2020).

Dentre os elementos que marcam esse esforço civilizatório que, mais tarde, seria recuperado pelas narrativas patrimoniais na Cidade de Goiás, além das igrejas, havia um famoso santeiro, José Joaquim da Veiga Valle (1806-1874), que produzia imagens para inúmeras irmandades e para os altares e oratórios particulares do vilaboenses.

A obra de Veiga Valle girou em torno da arte sacra. Defende-se que Veiga Valle era mais do que um confeccionador de cópias, pois, por mais que repetisse atitudes e atributos típicos da arte sacra, ele destacavase pelo acabamento e pela policromia de suas criações (Salgueiro, 1983). Sua obra é composta por uma variedade de santos, destacando as Madonas, representadas principalmente por Nossa Senhora d'Abadia, da Conceição, da Guia, do Bom Parto (figura 9: escultura em madeira, dourada e policromada, $140 \mathrm{~cm}$; Museu de Arte Sacra da Boa Morte, Cidade de Goiás), do Rosário, da Penha, das Mercês, do Rosário, entre outras. Além das Madonas, ele produziu imagens de São Sebastião, Cristo em Agonia, São Miguel Arcanjo, São José de Botas e São Joaquim e Meninos-Deus, (Santos, 2018). Boa parte de suas peças saiam nas procissões e em outras festas religiosas. 


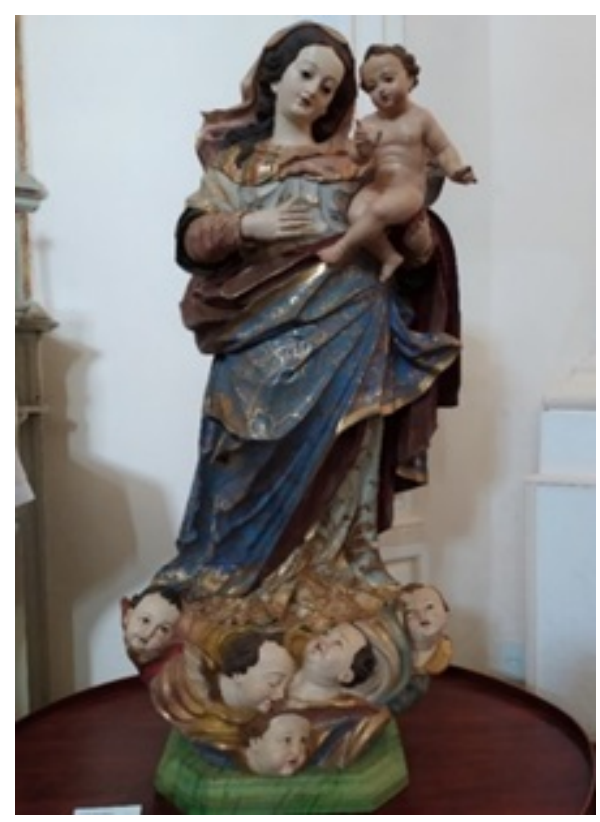

FIGURA 9

Nossa Senhora do Parto.

Fonte: Fernando Santos (2020).

As festas religiosas eram uma presença constante no cotidiano da população, possibilitando uma abertura estética para a música, para o teatro e para as artes plásticas. A quantidade de igrejas que, mesmo com a simplicidade de sua arquitetura, possibilitava que a população desfrutasse de ornamentos, oferecia certo deleite estético (Santos, 2018). Essa diversidade artístico-cultural, embora ainda fortemente dependente das igrejas, é um forte argumento, por um lado, contra as leituras que ressaltam a decadência, o atraso ou isolamento cultural de Goiás, que seria utilizado para transferir a Capital; por outro, é também base dos esforços de reconhecimento, pelo SPHAN, do patrimônio histórico e artístico nacional na cidade nos anos 1940 e 1950.

\section{A transferênCIA DA CAPITAL E O SENTIMENTO DE PERDA}

De Vila Boa à Cidade de Goiás a região ficou sendo a capital de Goiás por mais de 200 anos, da colônia à república. No entanto, parte dos relatos dos viajantes, governadores ou presidentes da província sugeria que a cidade não tinha possibilidade de crescimento por estar cercada de serras, indefensável de um possível ataque, muito afastada dos principais centros econômicos e políticos e das condições sanitárias. O presidente da Província Miguel Lino de Morais, em 1830, fez um relato emblemático sobre as condições da capital goiana:

Quanto salubridade, não conheço, entre todos os lugares por onde tenho viajado (e não são poucos) um onde se reúnam tantas moléstias graves. Quase se pode asseverar que não existe aqui um só homem são (...) Os meios de transporte são imperfeitos, a situação da cidade, encravada entre serras, faz com que sejam péssimas e de difícil trânsito as estrada que aqui chegam. Em uma palavra (...) Goiás não só não reúne as condições necessárias para uma capital, como ainda reúne muitas para ser abandonada. (Miguel Lino de Morais apud Chaul, 2001, p. 205).

Dada a narrativa de atraso e decadência, inúmeras vezes se aventou a transferência da Capital. No governo do Conde dos Arcos (1749-1755), já se cogitava a possibilidade de mudar o centro administrativo colonial para Meia Ponte (Pirenópolis). No governo de Miguel Lino de Morais (1827-1831), a proposta era que a capital se mudasse para a cidade de Água Quente, uma região mais povoada e de comércio intenso. Mesmo não efetivando nenhum dos projetos, a ideia da transferência da capital permaneceu na mente dos políticos 
goianos, o que explica o fato de, no artigo $5^{\circ}$ do texto constitucional (no anteprojeto de 1891 e nas reformas de 1898 e 1918), a decisão de que a Cidade de Goiás seria capital enquanto outra causa não deliberasse o Congresso (Chaul, 2001).

Quando Pedro Ludovico tomou posse do poder, na década de 1930, a transferência da Capital foi concretizada. Pedro Ludovico assumiu o governo com a Revolução de 1930, quando foi nomeado interventor do Estado de Goiás por Getúlio Vargas, quebrando o ciclo de domínio político da família Caiado. Oposto aos Caiado, o interventor visava romper os laços com o poder da situação até então. Ligado às influências das transformações cariocas, Ludovico, além de médico, havia se aliado também a outros opositores do grupo "caiadista", que se mantivera até 1930, quando foram depostos pelos movimentos da revolução nacional e regional (Gomide, 1999).

A mudança de capital passou a ser um dos seus principais projetos de governo, pois funcionava como um símbolo de ascensão ao poder, uma representação do progresso, do moderno, um divisor de águas entre o velho e o novo Goiás (Chaul, 2001, p. 210).

Em 1933, uma comissão decidiu que a nova Capital seria em um local com água abundante, perto da estrada de ferro, topografia adequada e bom clima. No mesmo mês, o governo autorizou a contratação de empréstimo de, no máximo, seis mil contos de réis para edificar a Capital. Em maio, foi assinado o Decreto no 3359 , que estabelecia as bases para edificar a nova Capital e, de acordo com o Artigo 1", "A região do córrego Botafogo, compreendida nas fazendas denominadas Criméia, Vaca Brava e Botafogo, no município de Campinas, fica escolhida para nela ser a futura Capital do Estado”. Em 24 de outubro, é lançada a Pedra Fundamental da nova Capital (Câmara, 1979, p. 68).

O município de Goiânia foi criado em 1935 e o Venerando de Freitas Borges foi nomeado como Prefeito. Pedro Ludovico transferiu sua residência para a nova Capital, com a intenção de acompanhar pessoalmente o andamento das construções. A repercussão foi profunda em Vila Boa e a cada dia a população percebia a inflexibilidade de Pedro Ludovico, passando a admitir que a transferência era um caminho sem volta (Santos, 2018). Aos poucos, os órgãos oficiais eram retirados da Cidade de Goiás e transferidos para Goiânia. Em 1937, ocorreu a transferência do legislativo e do judiciário e a transferência definitiva da capital da Cidade de Goiás para Goiânia.

A mudança da capital atingiu em cheio os vilaboenses, pois, em razão da nova capital, muitos dos seus símbolos estavam sendo desconsiderados e, até mesmo, destruídos. Durante todo o período elas passaram por um "cotidiano de espoliação". Segundo Tamaso:

Entendo que durante o período de transição, o vilaboense foi sendo testemunha de um cotidiano de espoliação, uma vez que vivenciou, dia após dia, os serviços públicos sendo carregados da cidade de Goiás: o hospital, o Liceu de Goiás, o Grupo Escolar, as Faculdades de Direito, Farmácia, a Escola Técnica, a Delegacia Fiscal, a Administração dos Correios e Telégrafos, o Batalhão da Polícia Militar, a Banda da Polícia, etc. Sofreu o vilaboense com as ações políticas que os sobressaltava, transformando o cotidiano da cidade. Havia sempre a dúvida e o medo pairando no ar, o que mais será carregado daqui? (Tamaso, 2007, p. 99).

A principal estratégia para minimizar o sentimento de perda e abandono era reverter a imagem da Cidade de Goiás, vinculada ao atraso, à insalubridade e à degradação. Para isso, difundiu-se a ideia de que a cidade era o berço da cultura goiana, a matriz geradora da história das tradições goianas.

Uma das primeiras tentativas para sensibilizar os vilaboenses para a sua história e tradição foi feita através do Comitê Pró-Goiás, em 1936, quando o professor Luiz do Couto chamou a cidade de "Panteon venerável, onde jazem filhos ilustres que, na política, na ciência, e nas armas ergueram muito alto o seu símbolo de gloriosas tradições e de um passado venerando e imorredouro" (Luiz do Couto, s.d. apud Câmara, 1979, p. 208). O Comitê Pró-Goiás não conseguiu reverter a mudança da capital, mas teve sucesso em criar um novo imaginário para dar sentido identitário aos vilaboenses.

Incentivar a preservação da tradição envolve iniciativas para criar os lugares de memória. De acordo com Pierre Nora (1993), os lugares de memória surgem para se criar uma ideia de pertencimento, se tornar algo 
interno, psicológico. Afinal, a memória de uma pessoa, quando busca seu passado, é feita sob a perspectiva de algo que já passou e acaba usando o presente como principal referência. "A passagem de memória para história obrigou cada grupo a redefinir sua identidade pela revitalização de sua própria história” (Nora, 1993, p. 17). A Cidade de Goiás precisava de algo nesse sentido para manter sua sobrevivência, já que foi desprovida de um de seus maiores referenciais simbólicos quando deixou de ser capital. "Mas foram, sobretudo, os valores históricos e artísticos, atribuídos pelo SPHAN, que iniciaram as primeiras restituições simbólicas das perdas sofridas" (Tamaso, 2007, p.118).

\section{Notas finais: Cinco igrejas E Uma Santa - os PRimeiros tombamentos da Cidade DE GoIÁs.}

Em 1940, chegou à Cidade de Goiás, a serviço do SPHAN, o pintor e restaurador João José Rescala[2], para fazer um inventário dos bens artísticos da cidade, catalogando imóveis públicos e civis, possíveis candidatos a monumentos históricos. Com a visita de João José Rescala na cidade, a ideia de valorização das tradições vilaboenses foi se consolidando nas décadas de 1940 e início da década de 1950. Logo após o Batismo Cultural de Goiânia, em 1942, a Cidade de Goiás, a cada dia, ganhava novos valores, alterando a sua percepção para os seus moradores de "cidade degradada" e consolidando a imagem de "cidade histórica" (Tamaso, 2007).

No ano de 1942, um membro do Departamento Administrativo do Estado de Goyaz, Moisés Costa Gomes, fez um parecer em processo da Interventoria Federal, para que se concedesse um empréstimo à Cidade de Goiás, sugerindo ao Presidente Getúlio Vargas a "elevação de Goiaz a Monumento Histórico" (Tamaso, 2007, p. 120).

Para muitos intelectuais vilaboenses, a cidade, reconhecida como Monumento Histórico, voltaria a ser valorizada na sociedade goiana. Segundo Prats (1997), o patrimônio é pensando e produzido em momentos de tensão entre a razão e o sentimento, entre a reflexão e a vivência. Esse processo se afirma através de uma construção social e de uma invenção da realidade. No entanto, essa construção social não se entende sem uma intervenção, que pode ocorrer de forma mais ou menos direta, de uma hegemonia social e cultural, que, no caso da Cidade de Goiás era o grupo antimudancista. Esse mesmo grupo faz uma invenção da realidade, não se referindo somente a elementos, mas também, a composições, em que elementos são extraídos inalterados de sua realidade; porém, quando colocados em novo contexto, acabam por contribuir com uma nova realidade. Seria o que Prats coloca como uma descontextualização para uma recontextualização. A invenção é consciente de sua manipulação, já a construção é inconsciente e impessoal. No final, invenção e construção se complementam (Prats, 1997).

A ideia de patrimônio no Brasil tinha como referência Minas Gerais, quando o Serviço do Patrimônio Histórico e Artístico Nacional foi criada, em 1937. Segundo Marcia Chuva, essa centralidade mineira configurou-se nas representações do patrimônio histórico e artístico nacional, na qual a produção artística e arquitetônica mineira do século XVIII foi considerada pragmática e modelar para o restante do Brasil, e o patrimônio passou a ser analisado e comentado a partir do patrimônio mineiro (Chuva, 2009).

Com essa ideia de patrimônio referenciado em Minas Gerais, a Cidade de Goiás tinha todas as condições para ter alguns bens tombados - sua arquitetura era colonial, tendo como destaque as igrejas e as obras sacras de Veiga Valle, que logo passará a ser chamado de Aleijadinho goiano.

Sobre os bens tombados pelo SPHAN, Márcia Chuva (2009) aponta que eles:

(...) adquirem um novo valor e troca, relativo aos significados que passam a conter quando incluídos na categoria de patrimônio histórico e artístico nacional, garantindo a eles o lugar de preservação das lembranças (...). Tais bens tombados, pretende-se, figuram-se como marcos referenciais que consolidam tais lembranças, permanentemente atualizadas e reatualizadas para ganhar significação presente. Dessa forma, as ações implementadas junto ao Sphan forjam uma ideia de permanência no tempo, fazendo crer na possibilidade de o passado ser visto e experimentado no presente. (...) Na medida 
em que toda perda social da memória é uma espécie de reificação, e toda reificação é esquecimento e amnésia, trata-se, mais uma vez, de reafirmação das práticas de exclusão e de violência simbólica (Chuva, 2009, p.67).

Se, como já mencionado a primeira visita de um membro do SPHAN na Cidade, o pintor José Rescala, aconteceu em 1940, já a segunda visita ocorreria somente em 1948, na qual o arquiteto Edgar Jacintho da Silva foi enviado para fotografar as principais igrejas, casas e monumentos públicos. O trabalho feito por Rescala anos antes foi fundamental para os estudos prévios, sendo inclusive uma das recomendações feitas para Edgar Jacintho, antes de iniciar seus trabalhos (Tamaso, 2007). No seu relatório prévio, Edgar Jacintho para o SPHAN, foram observadas as características identificadas como tradicionais e predominantes na arquitetura da cidade, assim como feita a descrição dos monumentos considerados como de maior importância, nos escopos dos bens valorizados então pelo órgão: o Chafariz da Boa Morte, a Antiga Casa de Câmara e Cadeia, a Igreja da Nossa da Abadia e o Palácio do Conde dos Arcos - elementos que remetiam à herança colonial e que vinham sendo consagrados como patrimônio histórico e artístico nacional pela ação do Serviço.

Não ocorreu o tombamento histórico de toda a Cidade, como a historiografia indica que queriam muitos vilaboenses na época. Mas seguindo a orientação de Alcides da Rocha Miranda, que era o Chefe da Secção de Arte da Divisão de Estudos e Tombamento (DET), algumas igrejas, conjuntos paisagísticos e uma peça de Veiga Valle, também deveriam ser incluídos nos Livros do Tombo (Tamaso, 2007). Já no final do mesmo ano de 1948, iniciou-se a deliberação dos tombamentos para a inscrição nos Livros do Tombo. Porém, os tombamentos ocorreram formalmente pelo SPHAN apenas em 1950, no qual foram tombadas pelo órgão[3]: a Igreja de São Francisco de Paula, Igreja de Nossa Senhora do Carmo, Igreja de Nossa d'Abadia, Igreja da Boa Morte, Igreja de Santa Bárbara e uma imagem de Nossa Senhora do Rosário (na cidade era chamada Nossa Senhora do Parto, sendo imagem de Veiga Valle).

Tais tombamentos nos anos 1950 significaram um alento do processo de espoliação experienciado pela cidade, pois possibilitaram uma revalorização da Cidade de Goiás no contexto estadual e nacional como berço da cultura goiana, tendo o patrimônio material religioso como um dos principais representantes. Ainda segundo Chuva (2009), deve-se pensar nas "invenções do patrimônio" como uma forma de estabelecer uma identidade, uma memória. Esse patrimônio religioso se tornou referência simbólica, lugar de memória e tradições, da identidade vilaboense, acionado em uma perspectiva identitária e política, na reafirmação da importância do município.

Cabe destacar que não se optou por abordar a recepção dos vilaboenses em relação à patrimonialização das referências locais - tema que certamente merece atenção, mas que não foi o escopo desse artigo -, debruçando-se preferencialmente sobres esses tombamentos dentro das rotinas e consagrações das primeiras décadas de atuação do IPHAN. Com isso, é possível tratar tais tombamentos como exemplo, dentre tantos, de que o patrimônio é seleção: implica na adoção de critérios e valores determinados, na seleção de alguns bens em detrimento de outro, na agência e na exclusão de alguns atores sociais. Nesse sentido, deve-se salientar que há no patrimônio conflitos, às vezes tácitos, que indicam um lado seu diametralmente oposto à sua romantização: um lado perverso.

\section{REFERÊNCIAS}

Assis, Wilson Rocha. (2005). Estudos de História de Goiás. Goiânia, Editora Vieira.

Baltieri, R. (2014). José Rescala. In: Freire, Luiz Alberto Ribeiro; Hernandez, Maria Herminia Oliveira (Orgs). Dicionário Manuel Querino de arte na Babia. Salvador: EBA-UFBA, CAHL-UFRB, 2014. Disponível em: http ://www.dicionario.belasartes.ufba.br. Acesso em: 20 ago. 2020. 16:10:00.

Câmara, J. (1979). Os Tempos da Mudança. $3^{a}$ edição. Goiânia: Editora O Popular.

Chaul, N. F. (2001). Caminhos de Goiás: da construção da decadência aos limites da modernidade. Goiânia: Editora UFG. 
Chuva, M. R. R. (2009). Os arquitetos da memória: sociogênese das práticas de preservação do cultural no Brasil (anos 1930-1940). Rio de Janeiro: Editora UFRJ.

Coelho, G. (1999). Guia dos Bens Imóveis Tombados em Goiás. Goiânia: Instituto de Arquitetos do Brasil.

Etzel, E. (1974). O barroco no Brasil: Psicologia - Remanescentes. São Paulo: Melhoramentos, Ed. Universidade de São Paulo.

Frei Simão Dorvi. (s.d.). Antiga Igreja do Rosário, Cidade de Goiás. Cidade de Goiás. Figura 2.

Gomide, C. H. (1999). Centralismo politico e tradição histórica: cidade de Goiás (1930-1978). Dissertação (Mestrado em História das Sociedades Agrárias) - Universidade Federal de Goiás, Goiânia.

Mattos, R. J. da C. (1894). Chorographia Histórica da Província de Goyaz. Rio de Janeiro: Revista Trimestral do Instituto Histórico Geographico e Ethnographico do Brasil. Tomo 32, $2^{\circ}$ trimestre e Tomo 33, $1^{\circ}$ trimestre, 1874.

Nora, P. (1993). Entre a Memória e a História: A problemática dos lugares. Tradu: Yara Aun Khoury. In. Projeto História, São Paulo, s.n.

Oliveira, E. C. (2014). Um dia a igreja cai: a importância cultural dos templos religiosos na cidade de Goiás. In. Patrimônio e Memória, São Paulo, Unesp, v.10, n.1, p. 28-47, janeiro-junho, 2014.

Palacin, L. (1994). O Século do Ouro em Goiás. Goiânia: UCG.

Passos, E. C. de. (1968). Obras de Arte da Cidade de Goiás. Goiânia, GO: Gráfica Oriente Irmão Oriente Ltda.

Prats, L. (1997). Antropoligia y patrimônio. Barcelona, ESP: Editorial Ariel.

Salgueiro, H. A. (1983). A singularidade da obra de Veiga Valle. Goiânia: UCG.

Santos, F.M. (2018).Veiga Valle: Da morte do Homem ao Nascimento do Artista (1874-1983). Dissertação (Mestrado em Ciências Sociais e Humanidades na área interdisciplinar Territórios e Expressões Culturais no Cerrado) Universidade Estadual de Goiás, Anápolis. . (2020). Figuras 1, 3, 4, 5, 6, 7, 8, 9. Acervo particular.

Tamaso, I. (2007). Em nome do Patrimônio - Representações e apropriações da cultura na Cidade de Goiás. Tese (Doutorado em Antropologia Social) - Universidade de Brasília, Brasília.

Tirapeli, P. (2020). Patrimônio Religioso. In: Carvalho, Aline; Meneguello, Cristina (Org.). Dicionário Temático do Patrimônio: Debates Contemporâneos. Campinas, SP: Editora Unicamp.

\section{Notas}

[1] SPHAN - Serviço do Patrimônio Histórico e Artístico Nacional

[2] João José Rescala nasceu no Rio de Janeiro em 1910, era pintor, restaurador e professor de Teoria, Conservação e Restauração da Pintura na Escola de Belas Artes, da Universidade Federal da Bahia. Em busca de um melhor direcionamento à arte que vinha praticando, Rescala frequentou o Curso de Pintura da Escola Nacional de Belas Artes, aliou-se a um grupo de alunos que propuseram a formação de um movimento em prol ao modernismo carioca: O Núcleo Bernadelli (Baltieri, 2014).

[3] Juntamente com as cinco igrejas, também foi tombado o Quartel do XX. 